Can.J.Phys.Pharma./2016.

\title{
Is there a role of iNOS activation in the delayed antiarrhythmic effect of sodium nitrite?
}

Demeter-Haludka Vivien ${ }^{1}$, Juhász László ${ }^{1}$, Kovács Mária ${ }^{1}$, Gardi János ${ }^{2}$, Végh Ágnes ${ }^{1}$.

Department of Pharmacology and Pharmacotherapy ${ }^{1}$, First Department of Internal Medicine ${ }^{2}$, University of Szeged, Albert-Szent Györgyi Medical Centre, Szeged, Hungary

*Corresponding Author:

Prof. Dr. Ágnes Végh, Ph.D., D.Sc.

Department of Pharmacology and Pharmacotherapy

University of Szeged

Albert Szent-Györgyi Faculty of Medicine

Dóm tér 12, P.O. Box 427 ,

H-6720 Hungary

Tel: 3662455673

Fax: 3663454565

e-mail: vegh.agnes@med.u-szeged.hu 


\begin{abstract}
This study aimed to examine whether inducible nitric oxide synthase (iNOS) plays a role in the delayed antiarrhythmic effect of sodium nitrite. Twenty-one dogs were infused intravenously with sodium nitrite $(0.2 \mu \mathrm{mol} / \mathrm{kg} / \mathrm{min})$ for $20 \mathrm{~min}$, either in the absence $(n=12)$ or in the presence of the iNOS inhibitor S-(2-aminoethyl)-isothiourea (AEST; total dose: 2.0 $\mathrm{mg} / \mathrm{kg}$; i.v., $n=9)$. Control dogs $(n=12)$ were given saline. Twenty-four hours later, all the dogs were subjected to a 25 min period occlusion of the left anterior descending (LAD) coronary artery, followed by rapid reperfusion. Dogs treated with AEST and nitrite were received again AEST prior to the occlusion. Compared to the controls, sodium nitrite markedly reduced the number of ectopic beats, the number and incidence of ventricular tachycardia and the incidence of ventricular fibrillation during occlusion and increased survival (0\% vs. 50\%) from the combined ischaemia and reperfusion insult. Although AEST completely inhibited iNOS activity, the nitrite induced increased NO bioavailability during occlusion was not substantially modified. Furthermore, AEST attenuated but did not completely abolish the antiarrhythmic effect of nitrite. The marked delayed antiarrhythmic effect of sodium nitrite is not entirely due to the activation of iNOS; other mechanisms may certainly play a role.
\end{abstract}

Key words: arrhythmias, sodium nitrite, delayed protection, ischaemia/reperfusion, nitric oxide 


\section{Introduction}

There is experimental and clinical evidence that inorganic nitrite and nitrate, the natural products of nitric oxide (NO) metabolism, may serve as reservoirs of NO (Kevil and Lefer 2011). This would be particularly important under ischaemic conditions, when in the absence of oxygen, the generation of NO from NOS enzyme activation is limited, and when the drop in $\mathrm{pH}$ and oxygen tension favours the reduction of nitrite to NO (Zweier et al. 1995), thus providing better cardiac function during ischaemia (Lefer 2006; Lundberg et al. 2011).

Recently, we have shown that the intravenous infusion of sodium nitrite, in a concentration which does not significantly modify arterial blood pressure and coronary blood flow, profoundly reduced the severity of ventricular arrhythmias that resulted from a $25 \mathrm{~min}$ coronary artery occlusion and reperfusion in anaesthetized dogs (Kovács et al. 2015). This marked antiarrhythmic protection was associated with increased NO-mediated reduction in oxidative stress, perhaps through protein S-nitrosylation and/or S-glutathionylation (Kovács et al. 2015).

We have a number of evidence that in this dog model, preconditioning induced by various mechanical (coronary artery occlusion, cardiac pacing, exercise; Babai et al. 2000; Kis et al. 1999a,b; Végh et al. 1992a, 1994) and pharmacological stimuli (NO donors, statins; György et al. 2000; Kisvári et al. 2014), results in marked early and delayed antiarrhythmic effect (György et al. 2000; Végh et al. 1992a), and that this protection is associated with the maintenance of NO availability during ischaemia (Kiss et al. 2010). The importance of NO, both in the early and the delayed cardioprotection is well established (Bolli et al. 1997; Végh et al. 1992b; Végh and Parratt 1996). For example, we know that in the delayed effect, NO, generated by the preconditioning stimulus via the rapid activation of the endothelial nitric oxide synthase (eNOS), stimulates further NO synthesis by activating the inducible form of NOS (iNOS; Bolli et al. 1997), and perhaps eNOS as well (Kovács et al. 2013). This 
mechanism is certainly involved in the late antiarrhythmic effect, since the inhibition of iNOS activation attenuates or even abolishes the protection (Hajnal et al. 2005; Kis et al. 1999a,b; Végh et al. 1994).

There is also some evidence that sodium nitrite induces delayed protective effects in various experimental models (Shiva et al. 2007b). However, it is unknown, whether it can evoke delayed protection against arrhythmias, and if so, what mechanisms would play a role. It has been proposed that nitrite causes early mitochondrial S-nitrosylation, which is stable for $24 \mathrm{~h}$, and protects mitochondrial function, when the heart is subjected to ischaemia (Shiva et al. $1997 a, b)$. Although this mechanism seems to be very likely, we have now examined, whether iNOS, would also be involved in the delayed effect of nitrite. Therefore, we used S-(2aminoethyl)-isothiourea (AEST), a relatively selective inhibitor of iNOS. The changes in the severity of ischaemia and arrhythmias, in iNOS activity and in the plasma nitrate/nitrite levels were examined during the experiments.

\section{Materials and methods}

\section{Ethics}

The upkeep of the dogs was in accordance with the Hungarian law (XVIII/VI/31) regarding large experimental animals, which conforms to the Guide for the Care and Use of Laboratory Animals by the US National Institutes of Health (NIH publication No.85-23, revised in 1996), and conformed to the European Parliament Directive 2010/63/EU. All animal experiments were supervised and approved by the Department of Animal Health and Food Control of the Ministry of Agriculture and Rural Development (No.XIII/1211/2012) and the Ethical Committee for the Protection of Animals in Research of University of Szeged, Szeged, Hungary (No.I-74-5-2012).

\section{Surgical procedures}


Thirty-three adult mongrel dogs of either sex, with a mean body weight of $21 \pm 4 \mathrm{~kg}$ were used. The dogs were housed in a separated animal room (temperature: $10-20^{\circ} \mathrm{C}$, humidity: 40-70\%, lightening: $12 \mathrm{~h}$ per day, 2 animals per pen) for two weeks and fed a standard diet and ad libitum access to water. Food was withdrawn $24 \mathrm{~h}$ before anesthesia.

On the first day the dogs were lightly anaesthetized with sodium pentobarbitone $(30 \mathrm{mg} / \mathrm{kg}$; Euthasol 40\% i.v. A.U.V., Produlab Pharma B.V., Raamsdonksveer, The Netherlands). A polyethylene catheter was introduced into the jugular vein through which the drugs (sodium nitrite, AEST, saline) were administered intravenously. A Millar tip catheter ((5F, Millar Instruments Inc., Houston, TX, USA) was positioned into the left carotid artery for monitoring changes in arterial blood pressure.

On the second day, the dogs were re-anaesthetized with a bolus injection of sodium pentobarbitone $(30 \mathrm{mg} / \mathrm{kg}$, iv.), and the anesthesia was maintained with intravenous injections of a mixture of chloralose and urethane $(60$ and $200 \mathrm{mg} / \mathrm{kg}$ respectively; Sigma, St. Louis, MO, USA). The depth of anaesthesia was monitored by the examination of the cornea and pain reflexes as well as by the measurement of blood pressure, and when it was necessary, a further bolus injection of the anaesthetic was given. The dogs were ventilated with room air using a Harvard respirator (Harvard Apparatus, Natick, MA, USA) at a rate and volume sufficient to maintain arterial blood gases within normal limits (Végh et al. 1992). Body temperature was measured from the mid-oesophagus and maintained at $37 \pm 0.5{ }^{\circ} \mathrm{C}$.

A catheter (Cordis F4) was introduced into the right femoral artery to measure arterial blood pressure (systolic and diastolic). The Millar tip catheter (5F, Millar Instruments Inc., Houston, TX, USA), which had been introduced into the left carotid artery on day one, was now pushed into the left ventricle (LV) for measuring LV systolic and end-diastolic pressure as well as and $\mathrm{LV}$ positive and negative $\mathrm{dP} / \mathrm{dt}_{\max }$. Through the right jugular vein, another catheter was 
positioned into the coronary sinus to obtain blood samples for the measurement of plasma nitrate/nitrite (NOx) levels.

A thoracotomy was performed at the fifth intercostal space, the pericardium was transected and the heart was explored. The descending branch of the left coronary artery (LAD) was prepared for occlusion proximal to the first main diagonal branch.

The severity of myocardial ischaemia was assessed by the measurement of changes in the degree of electrical activation and in epicardial ST-segment using a composite electrode positioned within the potential ischaemic region as described in detail previously (Végh et al. 1992a). The composite electrode collects $\mathrm{R}$ waves from 28 epicardial points with a bipolar lead, and the degree of inhomogeneity of electrical activation is assessed as a time delay between the first and a last point activated under the electrode, and expressed in milliseconds. The electrode also contains 4 unipolar electrodes by which changes in epicardial ST-segment (in $\mathrm{mV}$ ) are assessed. A chest lead II standard electrocardiogram (Plugsys Hemodynamic Apparatus; Hugo Sachs Electronik, March-Hugstetten, Germany) was also recorded to measure heart rate (HR) and assess the number and severity of arrhythmias.

Ventricular arrhythmias were evaluated according to the Lambeth Conventions (Walker et al. 1998) with a modification as previously outlined (Végh et al. 1992a). Thus, the total number of ventricular premature beats (VPBs), the incidence and the number of episodes of ventricular tachycardia (VT), and the incidence of ventricular fibrillation (VF) were assessed during the occlusion period. During reperfusion, only the incidence of VF (which is a final event in this species) was determined. Dogs that were still alive 2 min after reperfusion (the end of the study) were considered to be survivors. Those dogs that survived reperfusion were euthanized by an excess dose of the anaesthetic. All recordings were assembled and evaluated by LabChart 7 (AD Instruments Pty Ltd, Bella Vista, Australia) software. 


\section{Determination of iNOS activity}

This was performed using the radio immunoassay method. The preparation of the myocardial tissue samples (200 mg) were identical as described previously (Kisvári et al. 2014). Total protein concentrations were determined by the method of Bradford.

The measurements were carried out in the absence of calcium and calmodulin using NOS activity assay kit (Cayman Chemical, Ann Arbor, MI, USA), based on the conversion of $\left[{ }^{3} \mathrm{H}\right]$ L-arginine to $\left[{ }^{3} \mathrm{H}\right]$ L-citrulline by NOS. To eliminate background NOS activity in control samples, $10 \mathrm{mmol} \mathrm{L-N}{ }^{\mathrm{G}}$-Nitro-arginine (L-NNA), a non-specific inhibitor of the NOS enzyme was given to the reaction mixture before the addition of the tissue extract. A liquid scintillation counter (Wizard ${ }^{\mathrm{TM}}$, PerkinElmer, Waltham, MA, USA) was used to detect the amount of radiolabeled L-citrulline formed during the reaction by iNOS, and expressed as the percentage of the total counts corrected with the background counts per minute.

\section{Assessment of plasma nitrite/nitrate (NOx) levels}

This was determined by Griess reaction as described previously (Kiss et al. 2010; Kisvári et al. 2014). Plasma samples were collected from the jugular vein (day one) and after thoracotomy (day two) from the coronary sinus at different time points as indicated in Figure 1). The absorbance of the azo-compound was measured spectrophotometrically at $540 \mathrm{~nm}$ using a microplate reader (FLUOstar OPTIMA, BMG LABTECH GmbH, Ortenberg, Germany). The total nitrate/nitrite $\left(\mathrm{NO}_{\mathrm{x}}\right)$ concentration $(\mu \mathrm{mol} / \mathrm{l})$ was determined using a standard calibration curve of $\mathrm{NaNO}_{2}$ and $\mathrm{NaNO}_{3}$ (Sigma, St Louis, MO, USA). Data were analyzed by OPTIMA (Control and Data Analyses; BMG LABTECH GmbH, Ortenberg, Germany) software.

\section{Experimental protocol}

A total number of 33 dogs were used and randomly divided into three groups. On day one the dogs were slightly anaesthetized and infused intravenously either with saline (control group; $n$ 
$=12)$ or sodium nitrite $\left(\mathrm{NaNO}_{2}\right.$ group; $\left.n=21 ; 0.2 \mu \mathrm{mol} / \mathrm{kg} / \mathrm{min}\right)$ for 20 minutes (Figure 1$)$. Twenty-four hours later all the dogs were subjected to a 25 min occlusion of the anterior descending branch of the left coronary artery (LAD), followed by rapid reperfusion. In 9 dogs out of the sodium nitrite treated dogs, S-(2-aminoethyl)-isothiourea (AEST+NaNO 2 group) was slowly injected (over $5 \mathrm{~min}$ ) intravenously in a total dose of $2 \mathrm{mg} / \mathrm{kg}, 5 \mathrm{~min}$ before the commencement of the sodium nitrite infusion. In these dogs, $24 \mathrm{~h}$ later, the same dose of AEST was given again in intravenous infusion for $30 \mathrm{~min}$, just prior to the coronary artery occlusion. The dose of AEST applied in the present study was identical that of used previously to inhibit iNOS activity (Kis et al. 1999). Since in that study we have proved that AEST given to control dogs (subjected only to ischaemia and reperfusion) does not modify arrhythmia severity (Kis et al. 1999), therefore in this work we did not include a separate AEST control group. Three dogs served as sham-operated (SO) controls (not included in the protocol figure); from these animals myocardial tissue samples were collected in order to determine iNOS activity in healthy myocardium.

At the end of the experiments the dogs were euthanized by an excess of the anaesthetic, and myocardial tissue samples (TS) were collected either 2 min after reperfusion (these animals were considered as survivors) or at the time when the fibrillation was observed for further analyses (Figure 1). Blood samples (BS) were also collected at different time points as indicated on the figure (Figure 1). In some dogs (at least 5 dogs in each group), the size of the area, affected by the occlusion, was assessed using the same method that has been described in detail previously (Végh et al. 1992a). In brief, at the end of the experiments the heart was removed, and Patent Blue V dye was infused into the re-occluded LAD artery, whereas saline was infused into the patent left circumflex (LCX) artery, at a pressure equivalent to that of mean arterial pressure. The dyed area was cut out and weighed, and the area at risk was expressed as a percentage of the left ventricular wall, together with the septum. 


\section{Statistical analysis}

The data were expressed as mean \pm SEM, and differences between means were compared by ANOVA for repeated measures and by one-way ANOVA as appropriate, using the Fisher post hoc and Bonferroni tests. The number of VPBs and the number of episodes of VT were compared using the Kruskal-Wallis test. The incidence of VT and VF, as well as survival from the combined ischaemia and reperfusion insult was compared by the Fisher Exact test. Differences between groups were considered significant at $P<0.05$.

\section{Results}

\section{Haemodynamic effects of intravenously administered saline, sodium nitrite and AEST}

These are illustrated in Table 1. Compared to the saline treated controls, the intravenous infusion of sodium nitrite resulted in significant reductions in arterial blood pressure and a slight increase in heart rate. AEST itself had no significant effect on any haemodynamic parameters, measured either on day one, i.e. prior to the infusion of sodium nitrite, or day two, i.e. just prior to the occlusion, but significantly attenuated the haemodynamic effects of the intravenously administered sodium nitrite.

\section{Haemodynamic changes following coronary artery occlusion}

These are shown in Table 2. In all groups, occlusion of the LAD resulted in significant reductions in arterial blood pressure, LVSP, positive and negative $\mathrm{dP} / \mathrm{dt}_{\max }$ and an increase in LVEDP, whereas the HR remained substantially unchanged. These haemodynamic alterations were somewhat less pronounced in dogs given sodium nitrite, $24 \mathrm{~h}$ previously. The administration of AEST in the nitrite treated dogs did not substantially modify the occlusioninduced haemodynamic changes compared either to the controls or the nitrite treated dogs.

\section{The severity of arrhythmias during coronary artery occlusion and reperfusion}


The number and the incidence of various types of arrhythmias, occurring during a 25 min occlusion are illustrated in Figure 2. In control dogs, there were a high numbers of VPBs and episodes of VT that were apparent in all the examined dogs. Furthermore, in 5 dogs out of the $12(42 \%)$ control animals, VF occurred during the occlusion period and the rest of the dogs fibrillated on reperfusion, thus no dog in this group survived the combined ischaemia and reperfusion insult. In contrast, dogs infused with sodium nitrite $24 \mathrm{~h}$ previously, exhibited only few ectopic beats and episodes of VT, which occurred in 2 of the $9(22 \%)$ nitrite treated dogs. Furthermore, in this group no dog fibrillated during occlusion and $50 \%$ of the animals survived reperfusion (Figure 2). When AEST was given both prior to the infusion of nitrite (on day one) and, 24h later, just before the occlusion, the number of ectopic beats and the episodes of VT, as well as the incidence of VT during occlusion were again increased, but remained still significantly less than in the untreated controls. Inhibition of iNOS with AEST did not significantly modify the protective effect of nitrite on the incidence of ischaemiainduced VF; i.e. in the presence of AEST only 1 nitrite treated dog out of the 9 dogs (11\%) fibrillated during occlusion. AEST, however, abolished the protective effect of nitrite on the reperfusion-induced VF. In the $\mathrm{AEST}-\mathrm{NaNO}_{2}$ group only one dog (11\%) survived the combined ischaemia and reperfusion insult.

\section{The severity of ischaemia during coronary artery occlusion}

This was assessed by measuring changes in epicardial ST-segment and in the degree of inhomogeneity of electrical activation (Figure 3). In control dogs, both the epicardial STsegment (Figure 3A) and the degree of inhomogeneity of electrical activation (Figure 3B) were rapidly elevated during the first $5 \mathrm{~min}$ of the occlusion, and reached a maximum value of around $11 \mathrm{mV}$ and $130 \mathrm{~ms}$, respectively, at the $5 \mathrm{~min}$ of ischaemia. The administration of sodium nitrite, $24 \mathrm{~h}$ previously, significantly suppressed these ischaemic changes; both the development and the absolute values of the elevation of the epicardial ST-segment and of the 
degree of inhomogeneity were much slower and less than in the controls. The administration of AEST almost completely abolished the anti-ischaemic effects of sodium nitrite.

\section{Changes in plasma nitrate/nitrite (NOx) levels}

These were determined both before and after the intravenous administration of sodium nitrite from the venous blood and also 24h later, before and after the occlusion of the LAD in blood samples taken from the coronary sinus, as shown in the protocol figure (Figure 1). In control dogs infused with saline intravenously, there were no significant differences between the baseline (pre-infusion) and the 20 min values of nitrate and nitrite levels. In contrast, the infusion of sodium nitrite significantly increased the plasma nitrate and nitrite, as well as NOx concentrations irrespective whether AEST was present or not (Figure 4).

Whereas on day one there were no significant differences between the baseline values of NO metabolites among the groups, on day two a marked difference occurred between the control and nitrite treated dogs in the NOx levels, measured just prior to the occlusion in the blood of the coronary sinus. Thus both in the nitrite and the $\mathrm{AEST}+\mathrm{NaNO}_{2}$ groups, there was a significant increase in the NOx levels that resulted primarily from the marked elevation in the nitrate levels, since the nitrite concentrations were almost the same in all groups as the day one baseline values. This result indicates that sodium nitrite, under oxygenated conditions, occurred as nitrate in the blood, $24 \mathrm{~h}$ later.

When the LAD coronary artery was occluded, in the control dogs both the nitrate and nitrite levels were significantly reduced, resulting in a marked decrease in NOx by the end of the occlusion period. Compared to these changes, in the nitrite treated dogs the nitrate concentrations were considerable decreased and the nitrite concentrations increased during coronary artery occlusion, suggesting a possibility for non-enzymatic NO formation under reductive conditions. Since, in these dogs the reduction in the nitrate concentrations was more marked than the increase in nitrite concentrations, the NOx levels showed also a decrease 
during the occlusion. Nevertheless, the NO bioavailability in the nitrite infused dogs was significantly higher during ischaemia than in the saline infused controls. The administration of AEST did not significantly modify the nitrite-induced changes in the level of NO metabolites.

\section{The effect of nitrite on iNOS activity}

This is illustrated in Figure 5. Compared to the sham operated controls, in samples taken from dogs subjected only to a 25 min occlusion and reperfusion insult, no significant changes could be observed in the activation of iNOS. The administration of nitrite resulted in a slight increase in iNOS activation, which was completely abolished by the administration of AEST.

\section{Area at risk}

There were no significant differences in the area at risk among the groups. Thus the risk area was $36 \pm 3 \%$ in the controls, $37 \pm 3 \%$ in the sodium nitrite, and $35 \pm 4 \%$ in the AEST + $\mathrm{NaNO}_{2}$ treated groups.

\section{Discussion}

The aim of the present study was to test the hypothesis in our canine model of ischaemia and reperfusion, whether the administration of sodium nitrite can produce delayed antiarrhythmic effect, and if so, whether this effect, similar to preconditioning, involves the activation of iNOS. This question was raised, because there is evidence, albeit in different models, that sodium nitrite evokes delayed cardioprotection (Shiva et al. 2007b; Shiva and Gladwin 2009), but the mechanism by which this protection attains, is not well understood. We do not know, whether nitrite itself, or after converting to NO would elicit the protection. It is also not clear, how this conversion will take place under physiological conditions? To give answers, at least a part of these questions, first we designed studies to examine the possibility, whether the activation of iNOS plays a role in the nitrite-induced delayed antiarrhythmic protection. 
This hypothesis was based on those previous findings which clearly showed that iNOS has a crucial role in the delayed cardioprotective effects of preconditioning (Bolli et al. 1997; Végh and Parratt 1996). It was proposed that the preconditioning stimulus, via the activation of eNOS, enhances the formation of NO, which is then stimulates iNOS (and most probably eNOS as well; Kovács et al. 2013), resulting in further NO generation (Bolli et al. 1997). This iNOS derived enhanced NO production certainly contributes to the protection $24 \mathrm{~h}$ later, when the hearts are subjected to an ischaemia and reperfusion challenge (Bolli et al. 1997; Végh et al. 1994). The evidence for this NO-induced NO formation via the activation of NOS enzyme isoforms, comes from the direct measurement of enzyme activity (Bolli et al. 1997; Kovács et al. 2013) and from the use of the relatively selective inhibitors of iNOS, such as aminoguanidine (Kis et al. 1999a) or S-(2-aminoethyl)-isothiourea (Hajnal et al. 2005; Kis et al. 1999b). However, as to whether sodium nitrite, infused $24 \mathrm{~h}$ prior to an ischaemia/reperfusion insult, uses the similar pathway to induce protection is not known, and to our best knowledge it has not yet been investigated.

We have found that sodium nitrite administered in dogs $24 \mathrm{~h}$ before coronary artery occlusion and reperfusion results in significant antiarrhythmic effect. Thus the number and incidence of the various types of arrhythmias, resulting from a 25 min occlusion and then reperfusion of the LAD, were markedly reduced compared with the untreated controls. Similarly, the infusion of nitrite significantly attenuated the ischaemic changes, assessed by measuring epicardial ST-segment and the degree of inhomogeneity of electrical activation. We have also found that AEST, given twice in dogs infused with sodium nitrite, only partially, but not completely abolished the protective effects of nitrite against arrhythmias. Thus in the presence of AEST there was an increase in the number of ectopic beats and of episodes of VT during occlusion, but these were still significantly less than in the controls (Figure 2). Furthermore, AEST did not substantially modify the protective effect of nitrite against the occlusion- 
induced VF, but it abolished the protection against the reperfusion-induced VF. AEST also reversed the anti-ischaemic effects of nitrite (Figure 3). Thus we may conclude that the activation of iNOS might have a role in the delayed antiarrhythmic effect of sodium nitrite.

This conclusion is supported by the results obtained from the measurement of iNOS activity. These show that sodium nitrite increased (although it was statistically not significant) the activity of iNOS. This increase was completely abolished in the presence of AEST; moreover, in the AEST treated dogs the iNOS activity was somewhat lower than in the sham-operated controls. This result confirms the findings of our previous studies that AEST is able to effectively block the activation of iNOS, and subsequently the iNOS-derived generation of NO, to which we attribute a key role in the delayed cardioprotection (Kis et al. 1999b; Végh et al. 1994). However, whereas AEST completely blocked the delayed antiarrhythmic effect of the preconditioning stimuli, such as cardiac pacing (Kis et al. 1999b) and treadmill exercise (Hajnal et al. 2005), it only attenuated the nitrite-induced late antiarrhythmic effect. This finding raises the possibility that, in some aspects, there might be a difference between the preconditioning and the sodium nitrite-induced protection, as regards the source of NO during ischaemia. Whereas in the preconditioning-induced delayed protection the iNOS-induced NO generation seems to have a mandatory role (Bolli et al. 1997; Dawn and Bolli 2002; Végh and Parratt 1996), since the inhibition of iNOS activation abolishes the protection (Kis et al. 1999a,b; Végh et al. 1994), in case of the nitrite evoked delayed protection the activation of iNOS to produce NO is probably less important, since after the complete inhibition of iNOS activity, the protection, at least against the occlusion-induced arrhythmias, is still present.

In order to examine the source of NO $24 \mathrm{~h}$ after the administration of sodium nitrite, we measured plasma nitrate and nitrite levels twice; i.e. on day one before and after the 20 min infusion of nitrite in the systemic blood, and also on day two, before and after a 25 min coronary artery occlusion in the blood of the coronary sinus. We have found that there were 
no significant differences among the groups in the baseline (pre-infusion) nitrate, nitrite and NOx levels. However, in dogs infused with nitrite, irrespective of the presence of AEST, the concentration of NO metabolites were markedly increased by the end of the infusion period compared with the saline infused controls (Figure 4). Twenty four hours later, when the level of these NO metabolites had been assessed again, now in the blood of the coronary sinus, we observed that in all groups the nitrite levels were almost the same as the basal plasma nitrite concentrations, $24 \mathrm{~h}$ previously (Figure 4). In contrast, the nitrate concentrations were highly elevated in the nitrite treated dogs compared with the controls. We think that by this time nitrite has converted to nitrate, and in the absence of food intake, the nitrate levels were only affected by the renal function over the $24 \mathrm{~h}$ observation period (Lauer et al. 2001). At this time, if the dogs had been subjected to coronary artery occlusion, the total nitrate/nitrite (NOx) concentrations were reduced in all groups compared to their corresponding preocclusion values, but in the nitrite treated dogs, NOx was significantly higher than in the untreated controls (Figure 4). Furthermore, the reduction in NOx of the nitrite infused animals resulted mainly from the marked decrease in nitrate concentrations, whereas the nitrite levels were rather increased, indicating that nitrate reduced to nitrite, and then possible to NO during occlusion. In contrast, in the control dogs the marked reduction in NOx, determined at the end of the occlusion period, resulted from a significant decrease in both the nitrate and nitrite concentrations (Figure 4).

What conclusions we may draw from these results? First, it seems that following nitrite administration, the majority of nitrite is converted to nitrate, and it remains and circulates in this form over the next $24 \mathrm{~h}$ period. We may speculate that even under normal, oxygenated conditions, a part of the infused nitrite may convert to NO, which reductive process largely depends on the nitrite reductase activity of deoxy-haemoglobin ( $\mathrm{Hb}$ ) and xanthine oxidoreductase (Dejam et al. 2004). We also know that the activity of these nitrite reductive 
mechanisms increases with decreasing $\mathrm{pO}_{2}$, and $\mathrm{pH}$, and with increasing $\mathrm{NAD}^{+}$concentration, which milieu is rather unusual under physiologic conditions (Dejam et al. 2004). Therefore, in the absence of direct measurement of NO formation and/or of nitrite reductase activity, we are not able to provide evidence for the existence of such a nitrite to NO conversion in our experiments, but of course, the possibility of this mechanism cannot be excluded. The possible operation of these abovementioned nitrite reductase mechanisms (Lauer et al. 2001) in our experiments is supported by the fact that we have found an increase in iNOS activity $24 \mathrm{~h}$ after nitrite administration, which almost certainly resulted from the enzyme stimulation by NO (Figure 5). This enzyme activation was completely abolished in the presence of AEST. Second, our results show that under ischaemic conditions the heart of the nitrite treated dogs uses nitrate as a primary source for NO production via its reduction to nitrite and then to NO. This non-enzymatic NO formation provides adequate amount of NO during occlusion and the subsequent reperfusion to elicit protection against the ischaemic changes and arrhythmias. The fact that a part of the protection, such as against the ischaemia-induced ventricular arrhythmias, has still remained in the presence of AEST, further that the complete inhibition of the activity of iNOS did not modify the nitrite-induced effects on the concentration of NO metabolites suggest that iNOS, and the iNOS derived NO has only a minor role in the nitriteevoked delayed antiarrhythmic protection during ischaemia. On the other hand, the fact that AEST markedly attenuated the nitrite-induced protection against the ischaemic changes and the reperfusion-induced severe ventricular arrhythmias suggests a role for iNOS-derived NO in the protective effect of nitrite. We suppose that this enzymatic NO formation becomes particularly important during reoxygenation, when the rapid change in the milieu stops the nitrate-nitrite-NO conversion that has provided NO during ischaemia. Thus under these conditions the blockade of the additional NO source (iNOS) would result in the abolition of the nitrite-induced protection. 
The first evidence that inorganic nitrites may provide delayed protection resulted from studies of Shiva and his colleagues (Shiva et al. 2007a,b; Shiva and Gladwin 2009). They showed in various in vitro and in vivo models that nitrite administered $24 \mathrm{~h}$ prior to ischaemia produces similar protection by the same mechanism as nitrite given acutely (Shiva and Gladwin 2009). They proposed that nitrite through S-nitrosylation of mitochondrial proteins, particularly complex I, mediates both the early and delayed protection (Shiva et al. 2007b). It was suggested that mitochondrial S-nitrosylation occurs rapidly following the administration of nitrite and it remains stable for $24 \mathrm{~h}$ (Shiva and Gladwin 2009). The role of S-nitrosylation as a potential mechanism in the acute effect of nitrite has been confirmed in our own studies as well. We have shown that when sodium nitrite was administered either prior to and during the occlusion, or just prior to reperfusion, provided a marked antiarrhythmic protection against the ischaemia and reperfusion-induced severe ventricular arrhythmias and this effect was associated with protein S-nitrosylation and glutathionylation (Kovács et al. 2015). Although the role of stable protein S-nitrosylation cannot be ruled out as one of the potential mechanisms for the explanation of the delayed cardioprotection resulted from nitrite administration (Shiva et al. 2007b), there is a lack of sufficient information how this prolonged protein S-nitrosylation would take place. The results of studies in vitro from the same group (Shiva et al. 2007a) suggest that deoxymyoglobin, which nitrite reductase activity is much higher than deoxyhemoglobin to reduce nitrite, would be the candidate for conserving and generating NO via nitrite reduction under physiological conditions (Shiva et al. 2007a). Although in the present study we did not assess protein S-nitrosylation, we are not fully convinced that same mechanism operates under in vivo conditions and fully explains the marked delayed antiarrhythmic effect of sodium nitrite. What we can propose as an alternative and/or additional hypothesis for the delayed protective effect of nitrite that results from the nitrite/nitrate measurements in our large animal experiments, is that under 
physiological conditions the majority of the infused nitrite converts to nitrate, and in this form is stored over the next $24 \mathrm{~h}$. This is supported by the fact that the nitrate, but not the nitrite levels were markedly increased $24 \mathrm{~h}$ after the infusion of nitrite. As to whether mitochondrial protein S-nitrosylation would take place before the conversion of nitrite to nitrate we do not know yet, but the possibility of such a mechanism cannot be excluded. This warrants further examination in our model. The results of the measurement of iNOS activity, however, suggest that a part of nitrite is most probably converted to NO, and this was sufficient to stimulate iNOS. The fact that AEST, although completely blocked the activity of iNOS, it did not modify the concentration of NO metabolites and the occlusion-induced arrhythmias suggests that iNOS has only a minor contribution to NO formation and the protection in the nitrite treated dogs. We propose that dogs treated with nitrite, use nitrate as a primary source of NO during ischaemia. This is converted back first to nitrite and then to NO, when reductive conditions attains, such as during coronary artery occlusion, when we could observed a marked reduction in the nitrate, and an increase in the nitrite concentrations.

In conclusion, the results of the present study provided evidence that, in contrast with preconditioning, the activation of iNOS does not play a mandatory role in the nitrite-induced delayed antiarrhythmic protection, since the blockade of iNOS activation only attenuated but not completely abolished the protection. To explore mechanisms, which may contribute to the marked delayed antiarrhythmic effect of sodium nitrite, warrants further investigations which are in progress.

\section{Acknowledgements}

This work was supported by the Hungarian Scientific Research Foundation (OTKA; Project number K105252). Dr. Mária Kovács was supported by the MTA Postdoctoral Research Programme of the Hungarian Academy of Sciences We are also grateful to the excellent technical assistance of Erika Bakó and Irene Biczók. 


\section{References}

Babai, L., Szigeti, Z., Parratt, J.R., and Végh, Á. 2002. Delayed cardioprotective effects of exercise in dogs are aminoguanidine sensitive: possible involvement of nitric oxide. Clin. Sci. 102: 435-445. DOI: 10.1042/cs1020435

Bolli, R., Manchikalapudi, S., Tang, X.L., Takano, H., Qiu, Y., Guo, Y., Zhang, Q., and Jadoon, A.K. 1997. The protective effect of late preconditioning against myocardial stunning in conscious rabbits is mediated by nitric oxide synthase. Evidence that nitric oxide acts both as a trigger and as a mediator of the late phase of ischemic preconditioning. Circ. Res. 81: 1094-107. DOI: 10.1161/01.RES.81.6.1094

Dawn, B. and Bolli, R. 2002. Role of nitric oxide in myocardial preconditioning. Ann. N.Y. Acad. Sci. 962: 18-41. DOI: 10.1111/j.1749-6632.2002.tb04053.x

Dejam, A., Hunter, C.J., Schechter, A.N., and Gladwin, M.T. 2004. Emerging role of nitrite in human biology. Blood Cells Molecules and Diseases, 232: 423-429. DOI:10.1016/j.bcmd.2004.02.002

György, K.., Végh, Á.., Rastegar, M..A., Papp, J.Gy., and Parratt, J.R. 2000. Isosorbide-2mononitrate reduces the consequences of myocardial ischaemia, including arrhythmia severity: implications for preconditioning. Cardiovasc. Drugs Ther. 14: 481-488. DOI: 10.1023/A:1007832921391

Hajnal, Á., Nagy, O., Litvai, Á., Papp, J.Gy., Parratt, J.R., and Végh Á. 2005. Nitric oxide involvement in the antiarrhythmic effect of treadmill exercise in dogs. Life Sci. 77: 1960-1971. DOI:10.1016/j.lfs.2005.02.015

Kevil, C.G., and Lefer, D.J. 2011. Review focus on inorganic nitrite and nitrate in cardiovascular health and disease. Cardiovasc. Res. 89: 489-491. doi: $10.1093 / \mathrm{cvr} / \mathrm{cvq} 409$. 
Kis, A., Végh, Á., Papp, J.Gy., and Parratt, J.R. 1999a. Pacing-induced delayed protection against arrhythmias is attenuated by aminoguanidine, an inhibitor of nitric oxide synthase. Br. J. Pharmacol. 127: 1545-1550. . DOI: 10.1038/sj.bjp.0702695

Kis, A., Végh, Á., Papp, J.Gy., and Parratt, J.R. 1999b. Repeated cardiac pacing extends the time during which canine hearts are protected against ischaemia-induced arrhythmias: role of nitric oxide. J. Mol. Cell. Cardiol. 31: 1229-1241. DOI:10.1006/jmcc.1999.0955

Kiss, A., Juhász, L., Seprényi, Gy., Kupai, K., Kaszaki, J., and Végh Á. 2010. The role of nitric oxide, superoxide and peroxynitrite in the anti-arrhythmic effects of preconditioning and peroxynitrite infusion in anaesthetized dogs. Br. J. Pharmacol. 160: 1263-1272. DOI: 10.1111/j.1476-5381.2010.00774.x

Kisvári, G., Kovács, M., Gardi, J., Seprényi, Gy., Kaszaki, J., and Végh, Á., 2014. The effect of acute simvastatin administration on the severity of ventricular arrhythmias resulting from ischaemia and reperfusion in the canine: Is there a role for nitric oxide? Eur. J. Pharmacol. 732: 96-104. DOI: 10.1016/j.ejphar.2014.03.021.

Kovács, M., Gönczi, M., Kovács, E., and Végh Á. 2013. Time course analysis of cardiac pacing-induced gene expression changes in the canine heart. Mol. Cell. Biochem. 372: 257-66. DOI: $10.1007 / \mathrm{s} 11010-012-1467-8$

Kovács, M., Kiss, A., Gönczi, M., Miskolczi, G., Seprényi, G., Kaszaki, J., Kohr, M.J., Murphy, E., and Végh Á. 2015. Effect of sodium nitrite on ischaemia and reperfusioninduced arrhythmias in anaesthetized dogs: is protein S-nitrosylation involved? PLoS One, 24: 10(4):e0122243. DOI:10.1371/journal.pone.0122243

Lauer, T., Preik, M, Rassaf, T., Strauer, B.E., Deuson, A., Feelish, M., and Kelm, M. 2001. Plasma nitrite rather than nitrate reflects regional endothelial nitric oxide synthase activity but lacks intrinsic vasodilator action. Proc. Natl. Acad. Sci. U.S.A. 98: 1281412819. DOI: $10.1073 /$ pnas. 221381098 
Lefer, D.J. 2006. Nitrite therapy for protection against ischemia-reperfusion injury. Am. J. Physiol. Renal Physiol. 290: F777-F778. DOI: 10.1152/ajprenal.00470.2005

Lundberg, J.O., Carlström, M., Larsen, F.J., and Weitzberg, E. 2011. Roles of dietary inorganic nitrate in cardiovascular health and disease. Cardiovasc. Res. 89: 525-532. DOI: http://dx.doi.org/10.1093/cvr/cvq325

Shiva, S., and Gladwin, M.T. 2009. Nitrite mediates cytoprotection after ischemia/reperfusion by modulating mitochondrial function. Basic Res. Cardiol. 104: 113-119. DOI: 10.1007/s00395-009-0009-3

Shiva, S., Huang, Z., Grubina, R., Sun, J., Ringwood, L.A., MacArthur, P.H., Xu, X., Murphy, E., Darley-Usmar, V.M., and Gladwin, M.T. 2007a. Deoxymyoglobin is a nitrate reductase that generates nitric oxide and regulates mitochondrial respiration. Circ. Res. 100: 654-661. DOI: 10.1161/01.RES.0000260171.52224.6b

Shiva, S., Sack, M.N., Greer, J.J., Duranski, M., Ringwood, L.A., Burwell, L., Wang, P.H. et al. 2007b. Nitrite augments tolerance to ischemia/reperfusion injury via the modulation of mitochondrial electron transfer. J. Exp. Med. 204: 2089-2012. DOI: 10.1084/jem.20070198

Végh, Á., Komori, S., Szekeres, L., and Parratt, J.R. 1992a. Antiarrhythmic effects of preconditioning in anaesthetised dogs and rats. Cardiovasc. Res. 26: 487-495. DOI: http://dx.doi.org/10.1093/cvr/26.5.487

Végh, Á., Papp, J.Gy., and Parratt, J.R. 1994. Prevention by dexamethasone of the marked antiarrhythmic effects of preconditioning induced $20 \mathrm{~h}$ after rapid cardiac pacing. Br. J. Pharmacol. 113: 1081-1082. DOI: 10.1111/j.1476-5381.1994.tb17104.x

Végh, Á. and Parratt, J.R. 1996. Delayed ischaemic preconditioning induced by drugs and by cardiac pacing. In. Myocardial Preconditioning. Edited by C.L. Wainwright and J.R. 
Parratt. R.G. Landes Company, Austin, Texas, U.S.A. pp. 251-261. DOI: 10.1007/9783-662-22206-5_14

Végh, Á., Szekeres, L., and Parratt, J.R. 1992b. Preconditioning of the ischaemic myocardium; involvement of the L-arginine - nitric oxide pathway. Br. J. Pharmacol. 107: 648-652. DOI: 10.1111/j.1476-5381.1992.tb14501.x

Walker, M.J., Curtis, M.J., Hearse, D.J., Campbell, R.W., Janse, M.J., Yellon, D.M. et al. 1998. The Lambeth Conventions: guidelines for the study of arrhythmias in ischaemia, infarction, and reperfusion. Cardiovasc. Res. 22: 447-455. DOI: http://dx.doi.org/10.1093/cvr/22.7.447

Zweier, J.L., Wang, P., Samouilov, A., and Kuppusamy, P. 1995. Enzyme-independent formation of nitric oxide in biological tissues. Nature Medicine, 1: 804-809. DOI:10.1038/nm0895-804 
Table 1. Haemodynamic effects of saline, sodium nitrite and sodium nitrite and S-(2-aminoethyl)-isothiourea (AEST)

\begin{tabular}{|c|c|c|c|c|c|c|c|c|c|c|}
\hline & \multicolumn{2}{|c|}{ Saline } & \multicolumn{2}{|c|}{$\mathrm{NaNO}_{2}$} & \multicolumn{4}{|c|}{$\mathrm{AEST}^{\S}$} & \multicolumn{2}{|c|}{$\mathrm{AEST}+\mathrm{NaNO}_{2}$} \\
\hline & \multirow[b]{2}{*}{ Baseline } & \multirow[b]{2}{*}{ Max change } & \multirow[b]{2}{*}{ Baseline } & \multirow[b]{2}{*}{ Max change } & \multicolumn{2}{|c|}{ Day 1} & \multicolumn{2}{|c|}{ Day 2} & \multirow[b]{2}{*}{ Baseline } & \multirow[b]{2}{*}{ Max change } \\
\hline & & & & & Baseline & Max change & Baseline & Max change & & \\
\hline SABP (mmHg) & $148 \pm 6$ & $3 \pm 2$ & $155 \pm 6$ & $-11 \pm 4^{*}$ & $161 \pm 5$ & $-1 \pm 4$ & $142 \pm 4$ & $5 \pm 6^{*}$ & $153 \pm 3$ & $-3 \pm 3^{\dagger}$ \\
\hline DABP $(\mathrm{mmHg})$ & $100 \pm 6$ & $3 \pm 2$ & $122 \pm 4$ & $-7 \pm 2^{* \#}$ & $129 \pm 4$ & $-4 \pm 2^{* \#}$ & $101 \pm 5$ & $5 \pm 6^{*}$ & $117 \pm 3$ & $-2 \pm 2^{\# \dagger}$ \\
\hline MABP (mmHg) & $116 \pm 6$ & $3 \pm 2$ & $133 \pm 5$ & $-8 \pm 3^{*}$ & $140 \pm 4$ & $-3 \pm 2^{* \#}$ & $115 \pm 4$ & $4 \pm 6^{*}$ & $136 \pm 3$ & $-3 \pm 2^{\# \dagger}$ \\
\hline HR (beats/min) & $159 \pm 5$ & $3 \pm 1$ & $166 \pm 6$ & $6 \pm 2^{* \#}$ & $187 \pm 7$ & $-13 \pm 3^{* \#}$ & $166 \pm 2$ & $-2 \pm 2^{*}$ & $173 \pm 4$ & $-3 \pm 3^{\# \dagger}$ \\
\hline
\end{tabular}

Values are mean \pm SEM, calculated from $n=8$ experiments. ${ }^{*} P<0.05$ vs. baseline value, $\# P<0.05$ vs. control group, $\dagger P<0.05$ vs. NaNO2 group. Abbreviations: SABP: systolic arterial blood pressure, DABP: diastolic arterial blood pressure, MABP: mean arterial blood pressure, HR: heart rate. $\mathrm{AEST}^{\S}$ : These data represent the acute haemodynamic effects of AEST, when it was given before the administration of sodium nitrite (day 1), and 24h later (day 2), when it was infused for $30 \mathrm{~min}$ prior to occlusion in the nitrite treated dogs. 
Table 2. Haemodynamic changes during a 25 min occlusion of the LAD

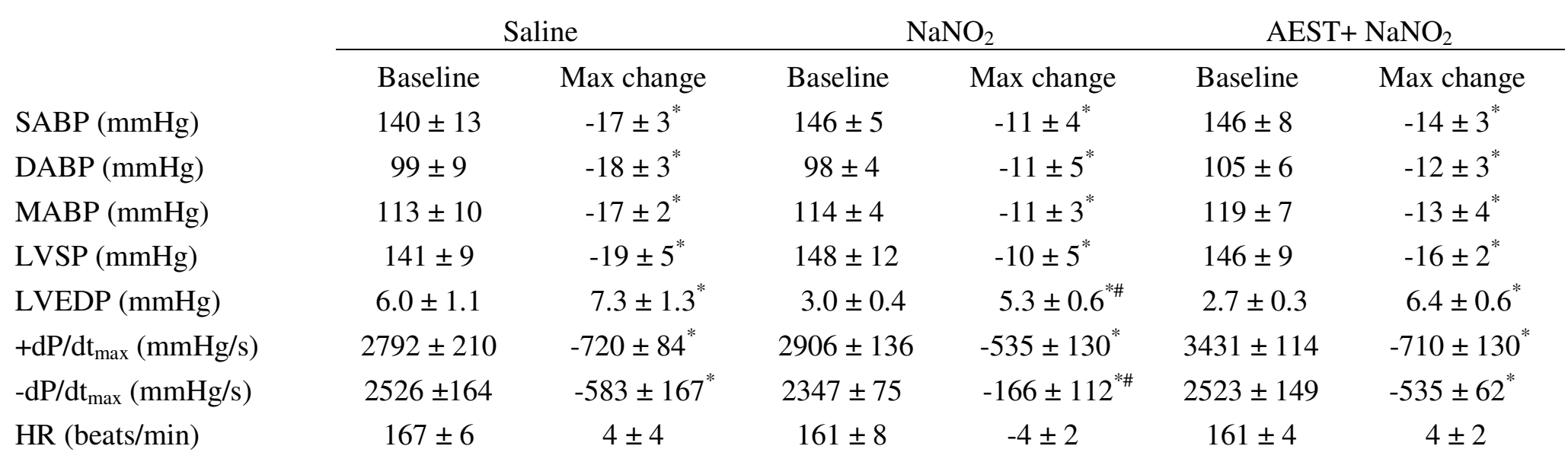

Values are mean \pm SEM, calculated from $n=8$ experiments. $* P<0.05$ vs. baseline value, $\# P<0.05$ vs. saline treated control group. Abbreviations: SABP: systolic arterial blood pressure, DABP: diastolic arterial blood pressure, MABP: mean arterial blood pressure, LVSP: left ventricular systolic pressure, LVEDP: left ventricular end-diastolic pressure, HR: heart rate. 


\section{Figure legends}

Figure 1. Experimental protocol. Three groups of dogs were used. On day one, control dogs $(n=12)$ were received saline in intravenous infusion over a 20 min period. In 21 dogs sodium nitrite was infused in a dose of $0.2 \mu \mathrm{mol} / \mathrm{kg} / \mathrm{min}$ ) for 20 minutes, either in the absence $\left(\mathrm{NaNO}_{2}\right.$ group; $\left.n=12\right)$ or in the presence of the iNOS inhibitor S-(2-aminoethyl)-isothiourea $\left(\mathrm{AEST}+\mathrm{NaNO}_{2}\right.$ group; $\left.n=9\right)$. AEST was slowly injected (over $5 \mathrm{~min}$ ) intravenously, in a total dose of $2 \mathrm{mg} / \mathrm{kg} 5 \mathrm{~min}$ before the commencement of the sodium nitrite infusion. Twentyfour hours later (day 2), all the dogs were subjected to a 25 min occlusion of the anterior descending branch of the left coronary artery (LAD), followed by rapid reperfusion. In the $\mathrm{AEST}+\mathrm{NaNO}_{2}$ group, AEST was given again in intravenous infusion for 30 min, just prior to the coronary artery occlusion. During the experiments blood samples (BS) were taken from the jugular vein before $(0 \mathrm{~min})$ and after $(20 \mathrm{~min})$ nitrite administration, as well as $24 \mathrm{~h}$ later from the coronary sinus in order to determine changes in nitrate/nitrite levels before ( $0 \mathrm{~min})$, and during $(7,12,17,25 \mathrm{~min})$ coronary artery occlusion, as well as immediately (1 min) following reperfusion. Myocardial tissue samples (TS) were collected either 2 min after reperfusion (these animals were considered as survivors) or at the time when the fibrillation was observed for further biochemical analyses.

Figure 2. The number and incidence of ventricular arrhythmias during a 25 min occlusion and reperfusion of the LAD in control, in sodium nitrite treated dogs $\left(\mathrm{NaNO}_{2}\right)$, and in dogs that infused with nitrite in the presence of AEST $\left(\mathrm{AEST}+\mathrm{NaNO}_{2}\right)$. Compared to the controls, nitrite significantly reduced the number and incidence of ventricular arrhythmias during occlusion and increased survival on reperfusion. AEST partially reversed the antiarrhythmic effect of nitrite during occlusion, but it abolished the protection against the reperfusioninduced arrhythmias. Values are means \pm S.E.M. ${ }^{*} P<0.05$ compared to the controls, ${ }^{\#} P<$ 0.05 compared to the nitrite-treated dogs. 
Figure 3. Changes in the epicardial ST-segment (A) and in the degree of inhomogeneity of electrical activation (B) during a 25 min occlusion of the LAD. Compared with controls, sodium nitrite significantly attenuated both indices of ischaemia severity. These effects of nitrite were markedly attenuated in the presence of AEST. Values are means \pm S.E.M. ${ }^{*} P<$ 0.05 compared to the controls.

Figure 4. Changes in nitrite $\left(\mathrm{NO}_{2}\right)$, nitrate $\left(\mathrm{NO}_{3}\right)$ and NOx plasma levels, determined in the venous blood before and after the administration of sodium nitrite, and also $24 \mathrm{~h}$ later, in the blood of the coronary sinus, before and after the occlusion of the LAD. Compared to the preinfusion values, the infusion of nitrite elevated the nitrite and nitrate levels, irrespective whether AEST was present or not. Twenty-four hours later, the nitrite concentrations in all groups were similar to the normal, initial values, whereas the nitrate levels were markedly elevated in the nitrite treated dogs. Occlusion of the LAD significantly reduced NOx in all groups, but the level of NO metabolites in the nitrite treated dogs were significantly higher than in the controls. These changes were also independent from the presence of AEST. Values are means \pm S.E.M. $* P<0.05$ compared to the pre-infusion (baseline) value of the corresponding group, ${ }^{\#} P<0.05$ compared to the pre-occlusion value of the corresponding group, and ${ }^{\dagger} P<0.05$ compared to the control group.

Figure 5. Changes in iNOS enzyme activity, determined by radioimmunoassay, in the shamoperated control $(n=3)$, in the ischaemic control $(n=6)$, and in the sodium-nitrite infused dogs without $\left(\mathrm{NaNO}_{2}, n=7\right)$ and with the administration of S-(2-aminoethyl)-isothiourea $\left(\mathrm{NaNO}_{2}+\mathrm{AEST}, n=6\right)$. Compared to the sham-operated group, there were no significant changes in iNOS activity in the ischaemic controls, but in the nitrite treated dogs a detectable, albeit statistically not significant, increase in enzyme activation could be observed. AEST completely inhibited the activation of iNOS, resulted from nitrite administration. Values are mean \pm SEM. $* \mathrm{P}<0.05$ compared to the $\mathrm{NaNO}_{2}$ group. 


\section{Page 27 of 31}

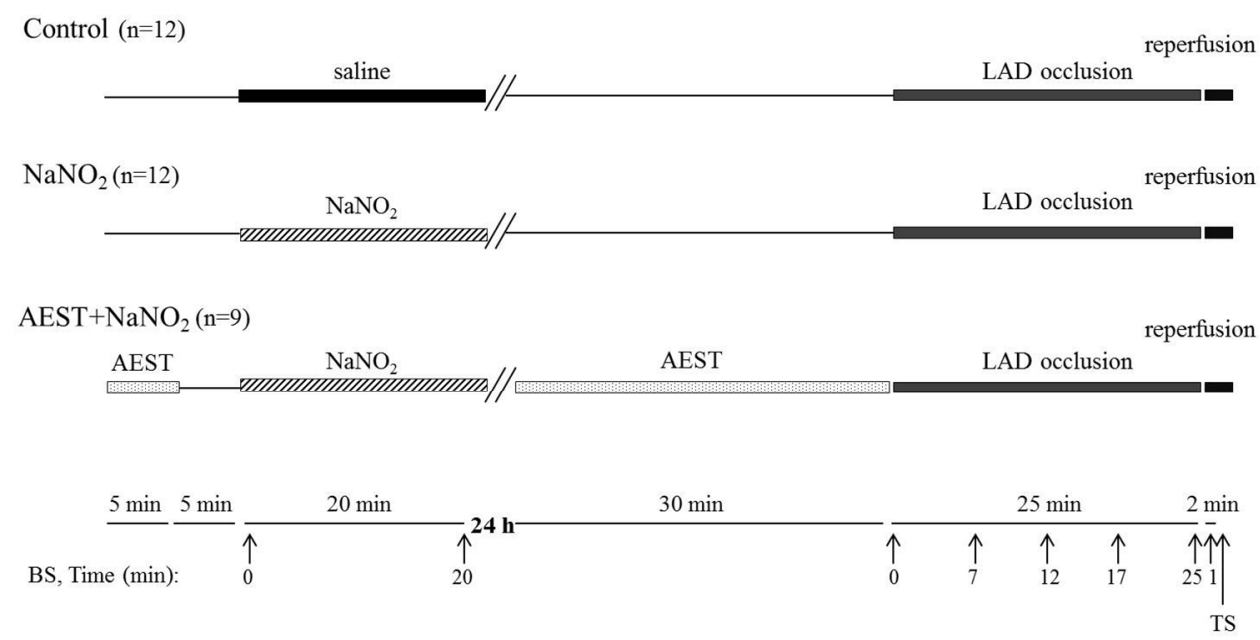

$127 \times 63 \mathrm{~mm}(300 \times 300 \mathrm{DPI})$ 

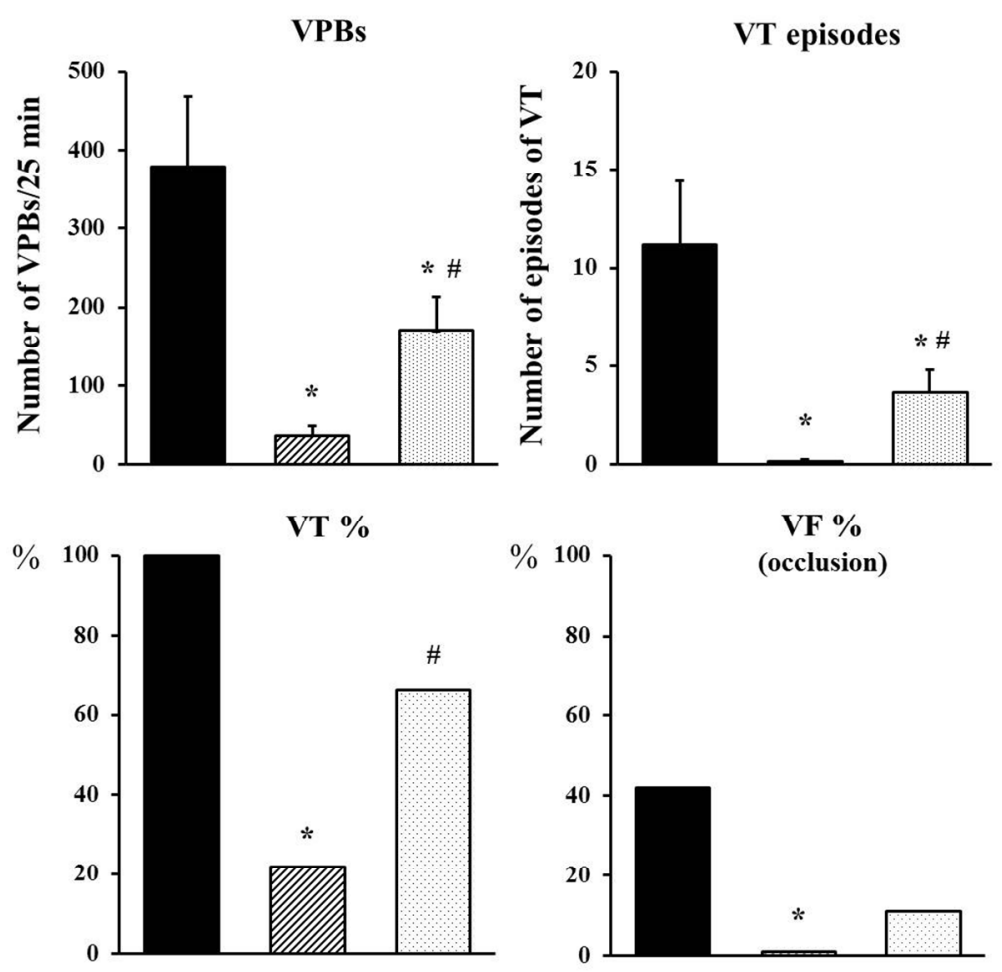

VF \%

SURVIVAL \%

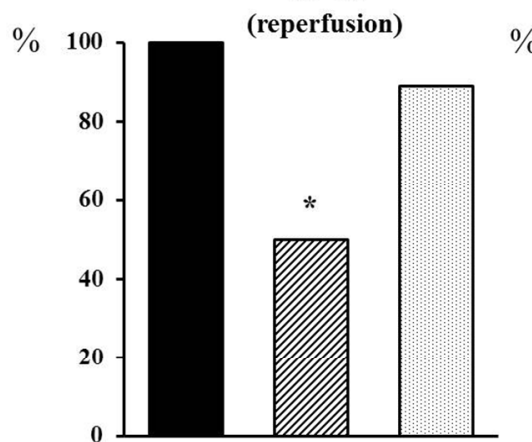

$\% \quad 100$

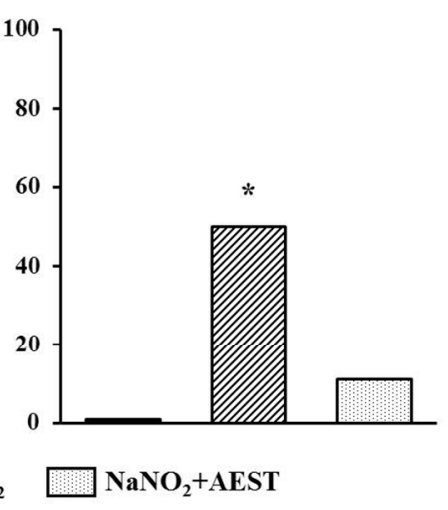

$88 \times 135 \mathrm{~mm}(300 \times 300$ DPI $)$ 

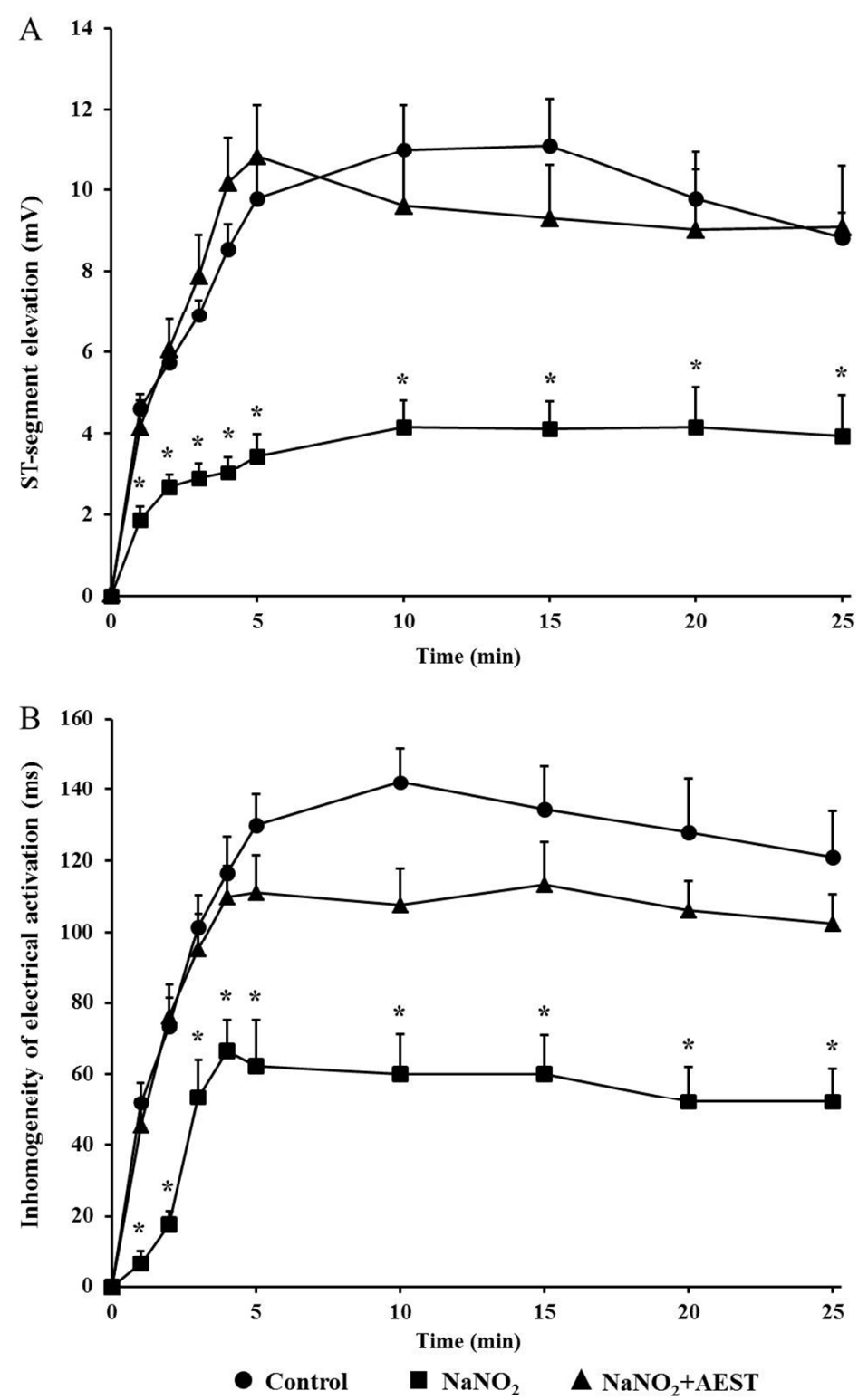

$87 \times 136 \mathrm{~mm}(300 \times 300 \mathrm{DPI})$ 

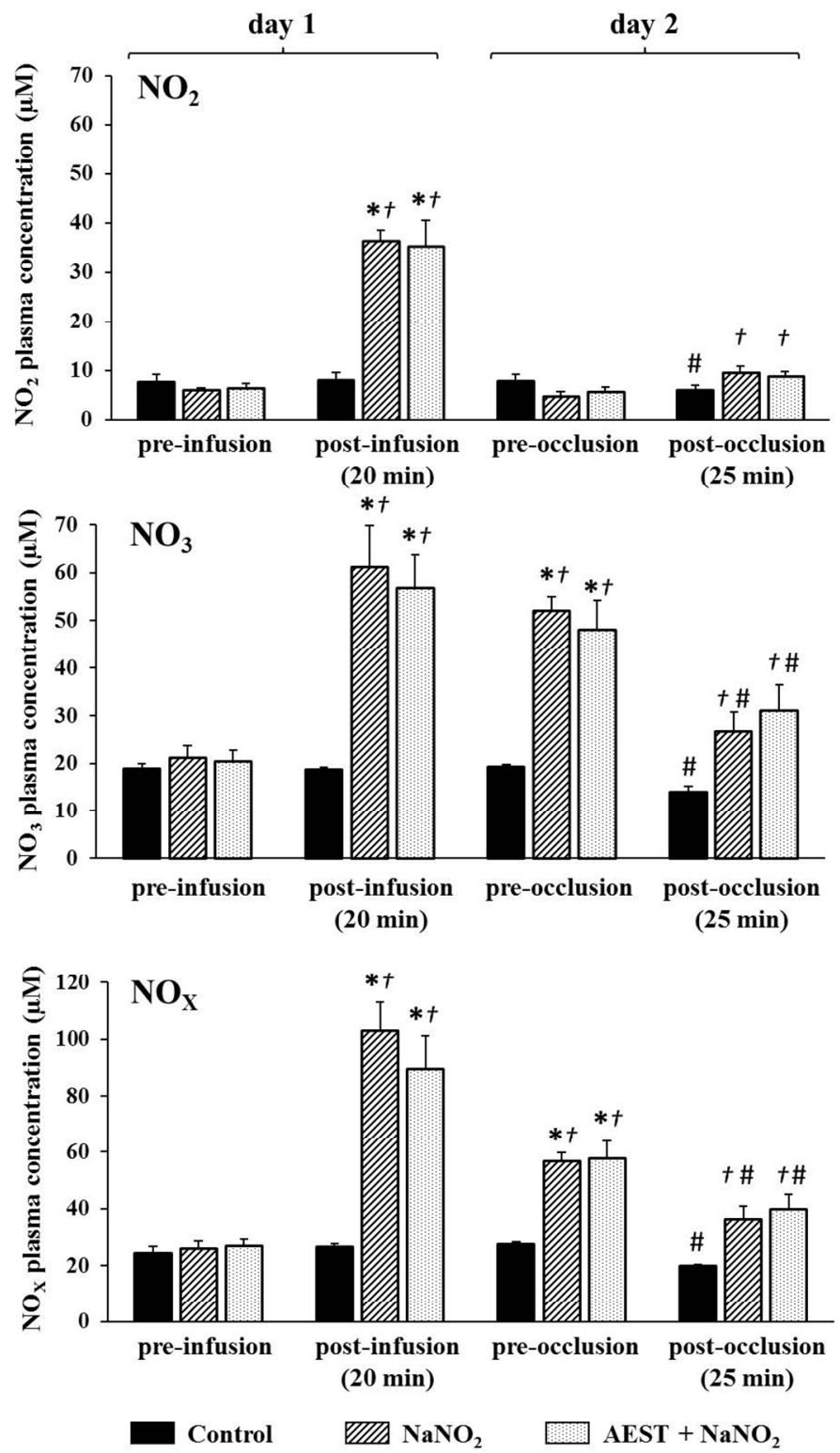

$85 \times 137 \mathrm{~mm}(300 \times 300 \mathrm{DPI})$ 


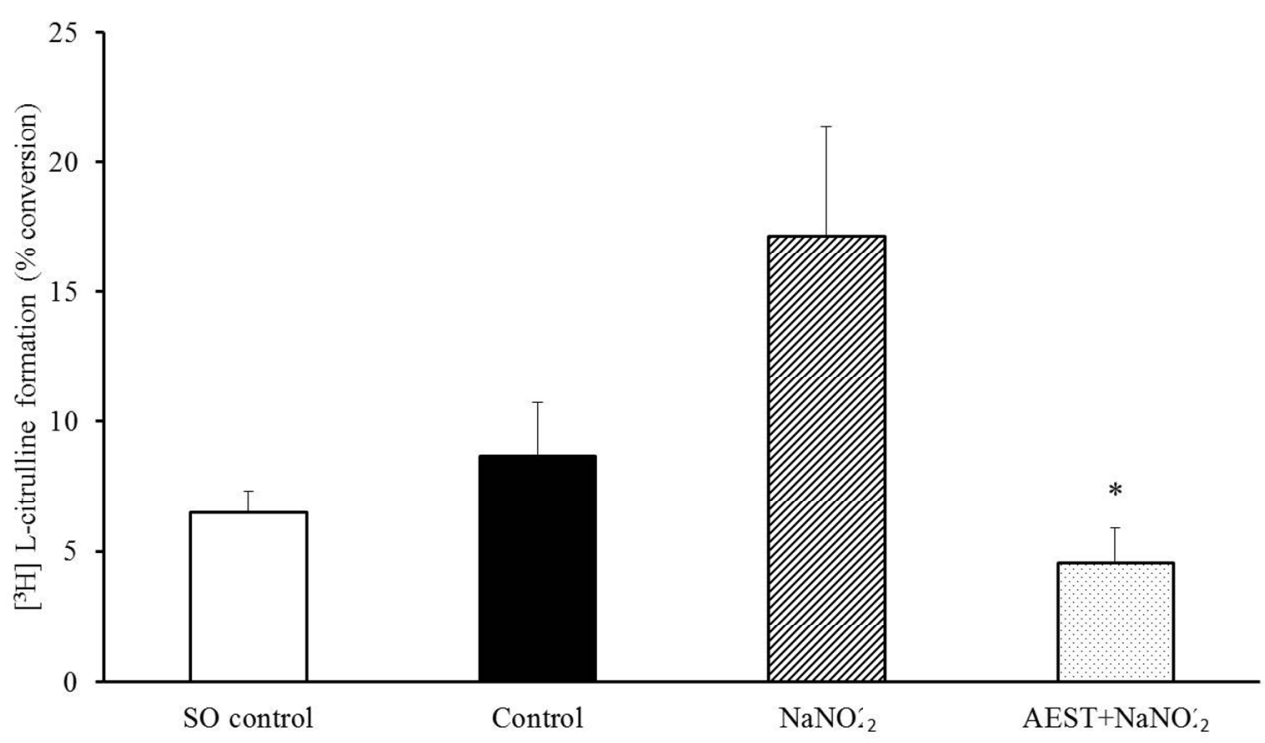

$107 \times 61 \mathrm{~mm}(300 \times 300 \mathrm{DPI})$ 